\title{
A novel mutation of $P A X 6$ identified in a Chinese twin family with congenital aniridia complicated with nystagmus
}

\author{
X. Cao ${ }^{1 *}$, X.M. Zhou ${ }^{1 *}$, R. Gan ${ }^{2 *}$, L.Q. Jiang ${ }^{2}$, L. Lu ${ }^{2}$, Y. Wang ${ }^{2}$, \\ N. Fan ${ }^{2}$, Y. Yin ${ }^{1}$, N.H. Yan ${ }^{1}$, W.H. Yu ${ }^{1}$ and X.Y. Liu ${ }^{2}$ \\ ${ }^{1}$ Ophthalmic Laboratories \& Department of Ophthalmology, \\ West China Hospital, Sichuan University, Chengdu, China \\ ${ }^{2}$ Shenzhen Key Laboratory of Ophthalmology, Shenzhen Eye Hospital, \\ Jinan University, Shenzhen, China \\ *These authors contributed equally to this study. \\ Corresponding author: X.Y. Liu \\ E-mail: xliu1213@126.com
}

Genet. Mol. Res. 13 (4): 8679-8685 (2014)

Received July 25, 2013

Accepted March 10, 2014

Published October 27, 2014

DOI http://dx.doi.org/10.4238/2014.October.27.8

\begin{abstract}
Genetic variations within the paired box gene 6 ( $P A X 6)$ gene are associated with congenital aniridia. To detect the genetic defects in a Chinese twin family with congenital aniridia and nystagmus, exons of $P A X 6$ were amplified by polymerase chain reaction (PCR), sequenced and compared with a reference database. Six members from the family of three generations were included in the study. The twins' father presented with congenital aniridia, nystagmus and cataract at birth, while the twins presented with congenital aniridia and nystagmus. A novel mutation c.888 ins A in exon 10 of $P A X 6$ was identified in all affected individuals. This study suggests that the novel mutation c.888 insA is likely responsible for the pathogenesis of the congenital aniridia and nystagmus in this
\end{abstract}


pedigree. To the best of our knowledge, this is the first report of this mutation in PAX6 gene in pedigree with aniridia. Furthermore, no PAX6 gene defect was reported in twins with congenital aniridia.

Key words: Congenital aniridia; Nystagmus; PAX6; Twin

\section{INTRODUCTION}

Aniridia is a severe ocular disease with an incidence of 1 in 60,000 to 100,000 people (Song et al., 2005). This disease is a congenital eye disorder characterized by the complete or partial absence of the iris and iris hypoplasia (Lee et al., 2008). Vision may be severely compromised and the disorder is frequently associated with a number of ocular complications: nystagmus, amblyopia, buphthalmos, and cataract (Ramaesh et al., 2005; Kokotas and Petersen, 2010).

PAX6 was originally defined by homology to Drosophila, paired as a member of the vertebrate paired box-containing $(P A X)$ family and mutations in this gene are known to cause developmental ocular disorders such as aniridia. (Ton et al., 1991; Walther et al., 1991; Chi and Epstein, 2002). It is located on chromosome 11p13, and spans $22 \mathrm{~kb}$ and consists of $14 \mathrm{ex}-$ ons and 13 introns (Epstein et al., 1994; Chi and Epstein, 2002). Human PAX6 is composed of two DNA-binding domains: the paired domain (PD) of 128 amino acids and the homeodomain (HD) of 61 amino acids separated by a linker region of 79 amino acids, and is followed by a proline-, serine-, threonine-rich (PST) domain of 79 amino acids that have a transcriptional transactivation function (Ton et al., 1991; Tang et al., 1998; Li et al., 2008) (Figure 1). Each of the domains seems to be the same important. (Simpson and Price, 2002). Mutation in any one of the domains is equivalent in effect (Simpson and Price, 2002). A large number of PAX6 mutations have been reported in patients with aniridia. Numerous mutations can be found in the Human PAX6 Mutation Database (http://lsdb.hgu.mrc.ac.uk/home.php?selectdb=PAX6) (Gronskov et al., 1999).

In this study, a novel PAX6 gene mutation was identified in a Chinese twin family with aniridia. Furthermore, to the best of our knowledge, no PAX6 gene defect was previously reported in twins with congenital aniridia.

\section{MATERIAL AND METHODS}

\section{Patients and clinical examination}

The study was approved by the Medical Ethics Committee of the Shenzhen Eye Hospital, Jinan University. Informed consent was obtained from all participants according to the principles of the Declaration of Helsinki. Three patients and three unaffected individuals were enrolled in this study. No consanguineous marriage was noticed in the family. The three patients and three unaffected individuals underwent a complete general ophthalmologic examination, including Snellen best-corrected visual acuity, intraocular pressure (IOP), anterior segment evaluation with slit-lamp microscopy, fundus examination, and B ultrasonic scan.

\section{Mutation screening and sequence analysis}


Genomic DNA was extracted from $200 \mu \mathrm{L}$ venous blood using a Qiamp Blood kit (Qiagen, Hilden, Germany). All procedures were performed according to manufacturer instructions. DNA integrity was detected by $1 \%$ agarose gel electrophoresis. Exons of the PAX6 gene and their adjacent splicing junctions were amplified from genomic DNA by polymerase chain reaction (PCR) using the forward and reverse primers that were modified from previous studies (Brown et al., 1998; Alward, 2000; Yan et al., 2011) (Table 1). PCR consisted of an initial denaturation step at $95^{\circ} \mathrm{C}$ for $2 \mathrm{~min}$, followed by 35 cycles of denaturation at $94^{\circ} \mathrm{C}$ for $10 \mathrm{~s}, 51-56^{\circ} \mathrm{C}$ for $30 \mathrm{~s}$ and extension at $72^{\circ} \mathrm{C}$ for $1 \mathrm{~min}$, and final extension at $72^{\circ} \mathrm{C}$ for 5 min. PCR products were directly sequenced using an ABI 377XL automated DNA sequencer (Applied Biosystems, Foster City, CA, USA). Sequence data were compared pair-wise with the published PAX6 sequence.

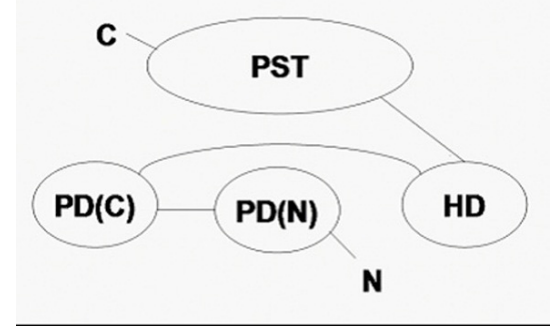

Figure 1. PAX6 protein contains 3 domain: a paired domain (PD), a homeodomain (HD), and a trans-activation domain (PST).

Table 1. Primers used in polymerase chain reaction for amplification of PAX6.

\begin{tabular}{|c|c|c|c|}
\hline PAX6 Exon & Primer direction & Sequence $\left(5^{\prime} \rightarrow 3^{\prime}\right)$ & Product size (bp) \\
\hline \multirow[t]{2}{*}{4} & Forward & AAGGGTAGATTTTGTATGCAC & 276 \\
\hline & Reverse & GAAGTCCCAGAAAGACCAGA & \\
\hline \multirow[t]{2}{*}{5} & Forward & CCTCTTCACTCTGCTCTCTT & 257 \\
\hline & Reverse & ATGAAGAGAGGGCGTTGAGA & \\
\hline \multirow[t]{2}{*}{$5 a$ and 6} & Forward & TGAAAGTATCATCATATTTGTAG & 515 \\
\hline & Reverse & AGGAGAGAGCATTGGGCTTA & \\
\hline \multirow[t]{2}{*}{7} & Forward & CAGGAGACACTACCATTTGG & 265 \\
\hline & Reverse & GACAGGCAAAGGGATGCAC & \\
\hline \multirow[t]{2}{*}{8} & Forward & GGGAATGTTTTGGTGAGGCT & 346 \\
\hline & Reverse & TCTTTGTACTGAAGATGTGGC & \\
\hline \multirow[t]{2}{*}{9} & Forward & GTAGTTCTGGCACAATATGG & 329 \\
\hline & Reverse & GCACTGTGTCTACGTCGAG & \\
\hline \multirow[t]{2}{*}{10 and 11} & Forward & CTCGACGTAGACACAGTGC & 437 \\
\hline & Reverse & TTATGCAGGCCACCACCAGC & \\
\hline \multirow[t]{2}{*}{12} & Forward & GCTGTGTGATGTGTTCCTCA & 245 \\
\hline & Reverse & AAGAGAGATCGCCTCTGTGC & \\
\hline
\end{tabular}

\section{RESULTS}

\section{Clinical findings}

Twin brothers, 12 years of age at the time of analysis, were diagnosed with aniridia and nystagmus at birth. Their corrected visual acuity was 0.1 OD and 0.1 OS. IOP of one twin 
(Figure 2, III-1) was $16.1 \mathrm{mmHg}$ OD and $14.4 \mathrm{mmHg}$ OS, while the other (Figure 2, III-2) was $13.7 \mathrm{mmHg}$ OD and $13.4 \mathrm{mmHg}$ OS. Clinical symptoms were identical in both brothers (Figure 3C-F). No abnormalities were detected in the lens, retina and optic nerve. B scanning suggested normal axial lengths.

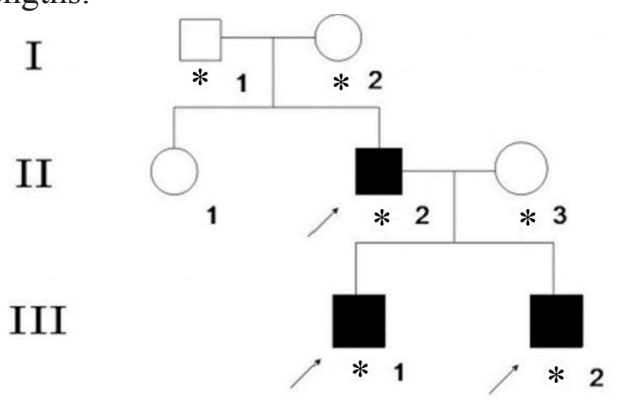

Figure 2. Pedigree of a Chinese family with aniridia and nystagmus. The filled squares and circles indicate affected individuals. Arrow indicates the proband. The asterisks indicate the individuals who had undergone clinical and molecular genetic analyses in the study.

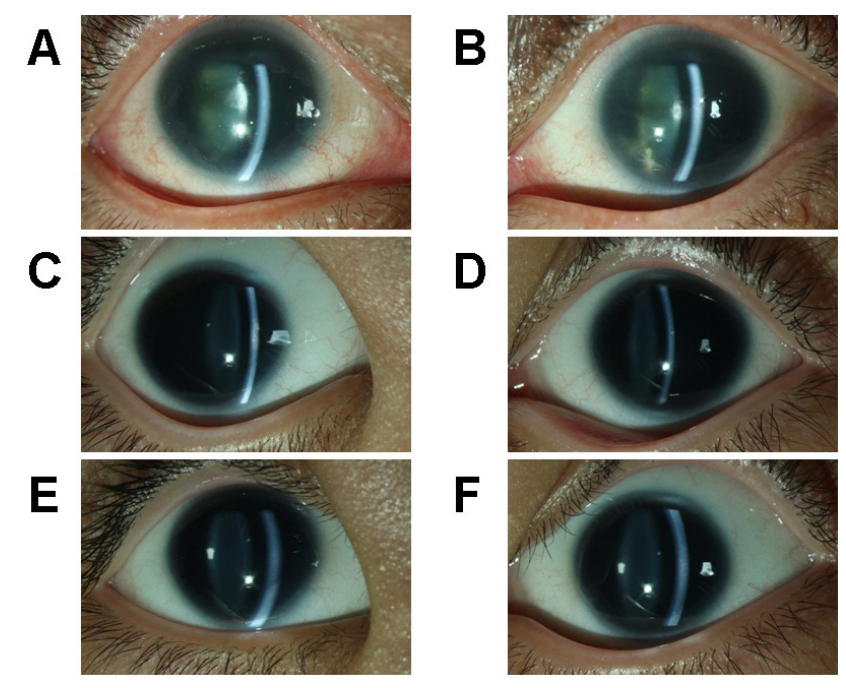

Figure 3. Iris photographs of three patients, A. B. the twins' father (II-2); C. D. twin (III-1); E. F. twin (III-2).

The twins' father (II-2) presented with aniridia, nystagmus, and cataract. His vision was hand motion OU, and IOP was $12.6 \mathrm{mmHg}$ OD and $12.5 \mathrm{mmHg}$ OS. Fundus details could not be seen. He suffered from nystagmus when he was born as noticed by his mother. Several months later, he was diagnosed with aniridia, nystagmus, and cataract (Figure 3 A, B). Ocular abnormalities were not found in the three unaffected members examined in this family.

\section{Mutation screening}


All exons of PAX6 of the affected and unaffected individuals included in this study were analyzed by direct sequencing. A heterozygous mutation, c.888 insA, was identified (Figure 4). The abnormality corresponding to exon 10 was detected in 3 aniridia patients, but was not detected in the 3 unaffected family members and in 100 unrelated Chinese individuals.

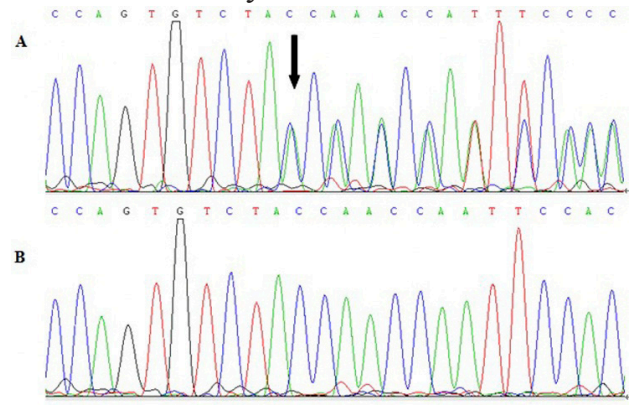

Figure 4. DNA sequence of a part of $P A X 6$ in the affected patients and unaffected individuals. A. A heterozygous insertion at nucleotide 888 (c.888 insA) in exon 10 of PAX6. Arrow indicates the location of the mutation. B. Normal sequence in control sample.

\section{DISCUSSION}

Aniridia is transmitted as an autosomal dominant trait among families in two-thirds of all patients, while other cases are sporadic (Nelson et al., 1984; Zhang et al., 2011). Dysfunction of $P A X 6$ causes defects during the development of the eye, since PAX6 mutations are known to cause iris anomalies and Peters' anomaly (Quiring et al., 1994; Yan et al., 2011). Most PAX6 mutations are found in exons 5-14 (Glaser et al., 1992; Jordan et al., 1992). The $P A X 6$ gene encodes a highly conserved transcriptional regulatory protein that is expressed in the developing eye, brain, spinal cord and pancreas (Boppana et al., 2012).

In the present study, the novel mutation (c.888 insA) identified generates a frameshift and a premature termination codon (PTC). Most point mutations will lead to a PTC in the PAX6 open reading frame, which cause over three-quarters of aniridia cases (Prosser and van Heyningen, 1998; Tzoulaki et al., 2005). Nonsense-mediated decay (NMD) is the process by which mRNAs containing PTCs are degraded before they produce large quantities of truncated proteins (Culbertson, 1999; Byers, 2002; Tzoulaki et al., 2005). NMD is a major mechanism acting on $P A X 6$ mutant alleles and consequently cause most truncated proteins to be produced at significantly lower levels in vivo (Tzoulaki et al., 2005).

Congenital aniridia is often correlated with cataract (Gupta et al., 1998; Gronskov et al., 1999; Song et al., 2005;), as occurred in the twins' father in this study. Song et al evaluated 81 different mutations in the PAX6 gene and 39 of them were accompanied with cataract. There were 18 accompanied with congenital or early cataract in the 39 cases (Song et al., 2005). It was concluded that missense mutations in PD and a reading frameshift in LNK or PST may be primary causes of congenital cataract, while missense mutations in exons 1-6 may cause less severe and more varied phenotypes, especially congenital cataract (Glaser et al., 1994; Azuma et al., 1999; Hanson et al., 1999; Gronskov et al., 1999; Neethirajan et al., 2003; Song et al., 2005). 
The twins' father presented with cataract at birth, while the twins did not. The underlying mechanism accounting for the difference between the twins and their father needs to be further explored. The same mutation in PAX6 has been reported in previous studies to cause different phenotypes (Vincent et al., 2004; Lin et al., 2011), and genotype-phenotype correlations are complicated (Tzoulaki et al., 2005; Lin et al., 2011). The mechanism of aniridia in patients with PAX6 mutation (c.577_578insG) reported by Bandah et al. (2008) may be either haploinsufficiency of the full-length $P A X 6$ protein or an aberrant ratio of full-length to paired-less protein isoforms. Various isoforms of PAX6 protein may be translated due to multiple alternative promoters and splice sites (Kim and Lauderdale, 2006; Bandah et al., 2007; Lakowski et al., 2007; Bandah et al., 2008). The isoforms were expressed together in various tissues and seem to functionally interact to regulate transcription of target genes (Chauhan et al., 2002a,b; Kiselev et al., 2012). Some of these transcripts have a unique expression pattern, which is highly conserved during evolution, but the transcripts have not yet been studied in humans (Lakowski et al., 2007; Bandah et al., 2008).

\section{Conflicts of interest}

The authors declare no conflict of interest.

\section{ACKNOWLEDGMENTS}

The authors are deeply grateful to all of the family members for their cooperation in this study. Research supported by grants from the National Natural Science Foundation of China (\#NNSF 81000370 and \#81200688).

\section{REFERENCES}

Alward WL (2000). Axenfeld-Rieger syndrome in the age of molecular genetics. Am. J. Ophthalmol. 130: 107-115.

Azuma N, Yamaguchi Y, Handa H, Hayakawa M, et al. (1999). Missense mutation in the alternative splice region of the PAX6 gene in eye anomalies. Am. J. Hum. Genet. 65: 656-663.

Bandah D, Swissa T, Ben-Shlomo G, Banin E, et al. (2007). A complex expression pattern of Pax6 in the pigeon retina. Invest. Ophthalmol. Vis. Sci. 48: 2503-2509.

Bandah D, Rosenmann A, Blumenfeld A, Averbukh E, et al. (2008). A novel de novo PAX6 mutation in an AshkenaziJewish family with aniridia. Mol. Vis. 14: 142-145.

Boppana S, Scheglov A, Geffers R and Tarabykin V (2012). Cellular retinaldehyde-binding protein (CRALBP) is a direct downstream target of transcription factor Pax6. Biochim. Biophys. Acta 1820: 151-156.

Brown A, McKie M, van Heyningen V and Prosser J (1998). The human PAX6 mutation database. Nucleic Acids Res. 26: 259-264.

Byers PH (2002). Killing the messenger: new insights into nonsense-mediated mRNA decay. J. Clin. Invest. 109: 3-6.

Chauhan BK, Reed NA, Yang Y, Cermak L, et al. (2002a). A comparative cDNA microarray analysis reveals a spectrum of genes regulated by Pax6 in mouse lens. Genes Cells 7: 1267-1283.

Chauhan BK, Reed NA, Zhang W, Duncan MK, et al. (2002b). Identification of genes downstream of Pax6 in the mouse lens using cDNA microarrays. J. Biol. Chem. 277: 11539-11548.

Chi N and Epstein JA (2002). Getting your Pax straight: Pax proteins in development and disease. Trends Genet. 18: 4147.

Culbertson MR (1999). RNA surveillance. Unforeseen consequences for gene expression, inherited genetic disorders and cancer. Trends Genet. 15: 74-80.

Epstein JA, Glaser T, Cai J, Jepeal L, et al. (1994). Two independent and interactive DNA-binding subdomains of the Pax6 paired domain are regulated by alternative splicing. Genes Dev. 8: 2022-2034. 
Glaser T, Walton DS and Maas RL (1992). Genomic structure, evolutionary conservation and aniridia mutations in the human PAX6 gene. Nat. Genet. 2: 232-239.

Glaser T, Jepeal L, Edwards JG, Young SR, et al. (1994). PAX6 gene dosage effect in a family with congenital cataracts, aniridia, anophthalmia and central nervous system defects. Nat. Genet. 7: 463-471.

Gronskov K, Rosenberg T, Sand A and Brondum-Nielsen K (1999). Mutational analysis of PAX6: 16 novel mutations including 5 missense mutations with a mild aniridia phenotype. Eur. J. Hum. Genet. 7: 274-286.

Gupta SK, De Becker I, Tremblay F, Guernsey DL, et al. (1998). Genotype/phenotype correlations in aniridia. Am. J. Ophthalmol. 126: 203-210.

Hanson I, Churchill A, Love J, Axton R, et al. (1999). Missense mutations in the most ancient residues of the PAX6 paired domain underlie a spectrum of human congenital eye malformations. Hum. Mol. Genet. 8: 165-172.

Jordan T, Hanson I, Zaletayev D, Hodgson S, et al. (1992). The human PAX6 gene is mutated in two patients with aniridia. Nat. Genet. 1: 328-332.

Kim J and Lauderdale JD (2006). Analysis of Pax6 expression using a BAC transgene reveals the presence of a paired-less isoform of Pax6 in the eye and olfactory bulb. Dev. Biol. 292: 486-505.

Kiselev Y, Eriksen TE, Forsdahl S, Nguyen LH, et al. (2012). 3 T3 cell lines stably expressing Pax6 or Pax6(5a) - a new tool used for identification of common and isoform specific target genes. PLoS One 7: e31915.

Kokotas H and Petersen MB (2010). Clinical and molecular aspects of aniridia. Clin. Genet. 77: 409-420.

Lakowski J, Majumder A and Lauderdale JD (2007). Mechanisms controlling Pax6 isoform expression in the retina have been conserved between teleosts and mammals. Dev. Biol. 307: 498-520.

Lee H, Khan R and O'Keefe M (2008). Aniridia: current pathology and management. Acta Ophthalmol. 86: $708-715$.

Li H, Leung CK, Wong L, Cheung CY, et al. (2008). Comparative study of central corneal thickness measurement with slit-lamp optical coherence tomography and visante optical coherence tomography. Ophthalmology 115: 796-801.

Lin Y, Liu X, Liang X, Li B, et al. (2011). PAX6 analysis of one family and one sporadic patient from southern China with classic aniridia. Mol. Vis. 17: 3116-3120.

Neethirajan G, Hanson IM, Krishnadas SR, Vijayalakshmi P, et al. (2003). A novel PAX6 gene mutation in an Indian aniridia patient. Mol. Vis. 9: 205-209.

Nelson LB, Spaeth GL, Nowinski TS, Margo CE, et al. (1984). Aniridia. A review. Surv. Ophthalmol. 28: 621-642.

Prosser J and van Heyningen V (1998). PAX6 mutations reviewed. Hum. Mutat. 11: 93-108.

Quiring R, Walldorf U, Kloter U and Gehring WJ (1994). Homology of the eyeless gene of Drosophila to the small eye gene in mice and Aniridia in humans. Science 265: 785-789.

Ramaesh K, Ramaesh T, Dutton GN and Dhillon B (2005). Evolving concepts on the pathogenic mechanisms of aniridia related keratopathy. Int. J. Biochem. Cell Biol. 37: 547-557.

Simpson TI and Price DJ (2002). Pax6; a pleiotropic player in development. Bioessays 24: 1041-1051.

Song S, Liu Y, Guo S, Zhang L, et al. (2005). A novel PAX6 gene mutation in a Chinese family with aniridia. Mol. Vis. 11: 335-337.

Tang HK, Singh S and Saunders GF (1998). Dissection of the transactivation function of the transcription factor encoded by the eye developmental gene PAX6. J. Biol. Chem. 273: 7210-7221.

Ton CC, Hirvonen H, Miwa H, Weil MM, et al. (1991). Positional cloning and characterization of a paired box- and homeobox-containing gene from the aniridia region. Cell 67: 1059-1074.

Tzoulaki I, White IM and Hanson IM (2005). PAX6 mutations: genotype-phenotype correlations. BMC Genet. 6: 27.

Vincent MC, Gallai R, Olivier D, Speeg-Schatz C, et al. (2004). Variable phenotype related to a novel PAX 6 mutation (IVS4+5G $>$ C) in a family presenting congenital nystagmus and foveal hypoplasia. Am. J. Ophthalmol. 138: 10161021.

Walther C, Guenet JL, Simon D, Deutsch U, et al. (1991). Pax: a murine multigene family of paired box-containing genes. Genomics 11: 424-434.

Yan N, Zhao Y, Wang Y, Xie A, et al. (2011). Molecular genetics of familial nystagmus complicated with cataract and iris anomalies. Mol. Vis. 17: 2612-2617.

Zhang X, Wang P, Li S, Xiao X, et al. (2011). Mutation spectrum of PAX6 in Chinese patients with aniridia. Mol. Vis. 17: 2139-2147. 